Title: Depathologizing sexualities: a relational autoethnography

First Author: Jaime Naish, BA (Hons)

Mental Health Nursing student

School of Health Sciences

University of Brighton

Email: J.Naish1@uni.brighton.ac.uk

Address: School of Health Sciences, Westlain House, University of Brighton, Village Way, Falmer, BN1 9PH, East Sussex

Second Author: Alec John Grant BA (Hons), MA, PhD, Cert Res Meth, PGCTLHE, FHEA, RMN, ENB650 Cert.

Reader in Narrative Mental Health

School of Health Sciences,

University of Brighton, UK

Email: A.Grant@brighton.ac.uk

Address: Dr Alec Grant, SHS(Nursing), University of Brighton, Robert Dodd, 49 Darley

Road, Eastbourne BN20 7UR, East Sussex

Third Author: Laetitia Zeeman B.Cur, M.Cur, D.Cur

Senior Lecturer in Mental Health

School of Health Sciences

University of Brighthon

Email: L.Zeeman@brighton.ac.uk

Address: Shool of Health Sciences, Westlain House, University of Brighton, Village Way, Falmer, BN1 9PH, East Sussex 


\title{
Depathologizing sexualities:
}

\section{a layered relational autoethnography}

\begin{abstract}
The aim of this relational autoethnographic paper is to critique heteronormative cultural assumptions informing mental health practice, from the standpoint positions of Queer scholarship. Those assumptions regard heterosexuality as the desired cultural norm and thus negatively impact on the wellbeing of people in lesbian, gay, bisexual, transgender, undecided and intersex (LGBTUI) communities. It will be argued that LGBTUI experiences of stigma are understandable in the context of the way people are pathologized on the basis of those assumptions. The paper concludes in a discussion of some emerging implications for mental health practice.
\end{abstract}

\section{Introduction}

Building on previous work (Grant 2013, Grant et al 2013, Grant et al in press) which exposed and interrogated stigmatizing mental health cultures, our aim in this paper is to use a Queer theoretical standpoint position to critique heteronormative assumptions and related practices in mental health. These assumptions have a historical basis, are reflected in mental health practice professional narratives, and impact negatively on mental health services users from in lesbian, gay, bisexual, transgender, undecided and intersex (LGBTUI) communities.

Methodologically, the paper employs relational autoethnographic principles (Grant et al 2013) in using a conversation between three people as a useful analytic strategy. This allows for theoretical and empirical material to illuminate subjective experiences and vice versa. Jaime, the first author, is a student mental health nurse who has a 'writing for publication' mentoring relationship with Alec and Laetitia, mental health/nurse academics experienced and published in relational autoethnographies of recovery, survival and related topics. Our conversation built on source data, which included email 
exchanges and attachments and Jaime's illustrated student assignments, which were in turn based on her practice experiences. The author sequence reflects the fact that Jaime's submitted assignment work initiated the process of co-constructing this paper and that Alec took the editorial lead in its final shaping and construction. Specific locations, times, and names have been disguised to protect anonymity, and all contributing authors are in full agreement on the publication of this paper in its present form.

Alec: I became interested in what you had to say in your assignments Jaime, because it chimed with my ongoing concerns. Along with Laetitia and other colleagues, I have for several years tried to write about the involvement of some of us with the mental health services, and life after, in increasingly existential rather than pathologizing ways (eg Grant and Zeeman 2012, Grant et $a$ l in press). I believe that such re-storying of our life narratives has enabled us to construct viable lives relatively independent of the institutional mental health system and services.

Our experiences and emancipatory writing and research led me to become increasingly interested in contemporary work that documents the challenge of uncoupling much human distress from pathologizing world views. This work takes issue with the extent to which the misery implicated in human existence is medicalized through psychiatric diagnoses (Rapley et al 2011, Johnstone 2014). The challenge to the psychiatrization of human misery has been more specifically nuanced and shaped for many years now on the basis of a wide range of inter-related sociocultural perspectives. These include cultural diversity (Fernando 2011), gender (Timimi 2011) and sexuality (Weeks 2000, Clarke et al 2010, Cromby et al 2013). Fundamental to these areas is, of course, the more insidious role of social control and compliance (Weeks 2000). 
Laetitia: In this regard, our lives are shaped within specific legal, institutional and organisational frameworks (Foucault 1974, 1978). So, mental health care, scholarship, research and related institutions can be regarded as component parts of a disciplinary society where confinement, surveillance, separation and classification constrain social behaviour as a way of maintaining order. Such 'disciplinary power' is exercised via biomedicine where bodies, desires and behaviour are regulated and arguably shaped on the basis of prevailing and enduring cultural norms.

Queer theory makes visible the processes that define the normal and the natural (Halperin 1997), and psychiatry has long been instrumental in upholding heterosexuality as the norm in this regard. As a result, the lives of those of us with a different sexual orientation became increasingly constrained, as the following experience illustrates.

'Homosexuality is a disease that can be cured' was the slogan of one of the many groups active in the USA, UK and South Africa during the 1970s-1990s in providing a 'cure' for homosexuality. At the time I lived in South Africa under the 'Apartheids' political regime. Any form of difference based on ethnicity and race, and also sexuality and gender, was suppressed, resulting in people becoming marginalised and silenced.

During this period, I was a final year student at university, and one evening I had arranged to meet a few friends at a gay club. As we stood talking later that night, the police entered the club, which was reasonably full, in riot gear. The music stopped, the lights were turned on, and the police instructed us to stand against a wall and face them. They took a photograph of each of us. Due to the tension felt in the club, we did not question the police or showed any form of resistance. After the photographs were taken, the police left as mysteriously as they appeared. 
In the early hours of the next morning, I returned to the halls of residence wondering if I would be excluded from university. Days turned into weeks and nothing came of the event, but I remained puzzled and fearful of the potential consequences. What did the police do with the images? The experience left such an impression on me that I avoided any contact with queer people for the remainder of my studies.

A few years later Nelson Mandela was released from prison and South Africa adopted a liberal constitution and a bill of human rights, where people were protected on grounds of race, ethnicity, sexuality, gender, age and other markers of difference. Changes to the political and legal structures meant norms could shift to bring greater appreciation of diversity. Surprisingly, South Africa became one of the first countries to legalise civil partnership and same-sex marriages.

Alec: So that experience compromised who you were Laetitia, in terms of forcing you to manage your social relationships much more carefully. How does that square with your experiences Jaime?

Jaime: Well, professionally, for the past nine years I have worked both on a voluntary and employed basis at a youth project, in the south of England. It supports young people who identify as lesbian, gay, bisexual, transgender, or unsure of their sexuality or gender orientation (LGBTU). Although identifying as LGBTU is not a mental health issue per se, people who do so are at greater risk of experiencing mental health issues due to discrimination and a long history of LGBTU marginalization within social structures (NHS choices 2014). 
Identity remains a key issue for young people from LGBTU communities, as sexual identities are in tension with heteronormative social structures, resulting in oppression and isolation (Browne and Lim 2008, Hunt \& Minsky 2007, Mayberry 2013, NHS choices 2014). Identity categories of people in the LGBTQI communities can result in them being objectified solely on the basis of their expressed sexual and gender orientations, by both lay and professional people. In this process, the social power of heterosexual identity is affirmed as 'normal', and LGBTBU people are seen as 'other' (Beasley 2005).

Laetitia: Along with several other colleagues, Alec and I have recently argued that psychiatry, which reflects social and cultural norms related to gender and sexuality, has long been instrumental in defining norms and delineating difference from those norms (Zeeman et al 2014a). However norms change over time, as seen in homosexual relationships being tolerated in ancient Greece, to homosexuality becoming illegal and later medicalized as a sexual disorder within psychiatric systems of diagnosis and classification, from the 1930s through to the 1970s (Johnstone 2014).

In consequence, lesbian, gay, bisexual, trans, queer and intersex people in the UK have long been the object of the biomedical clinical gaze and treated as 'other' as they differed from the heterosexual norm. Criminal convictions or referral for psychiatric treatment via court orders have derailed the lives of countless people due to condemnation of their homosexuality during the period from the 1930s to the 1970s (Giddens and Sutton, 2013). They were subjected to a range of biomedical interventions and psychological therapies in the UK, in order to cure their 'deviance'. This included aversion therapy, electroconvulsive therapy, frontal leucotomy and insulin treatment (Dickinson 2015). 
Thankfully, larger cultural and social shifts resulting in resistance to restrictive heterosexual norms became politicised by the gay liberation movement (Weeks 2000). This contributed to the decriminalisation of homosexuality in 1967 in the UK (Giddens and Sutton, 2013), and its declassification and removal as a sexual disorder from the diagnostic system of the American Psychiatric Association in 1974 (Johnstone 2014). By making the historical and cultural basis for the production of societal norms publicly visible, sexuality and gender can be reclaimed from the grasp of biomedicine. This emancipatory process continues, in the advance towards greater gender and sexual plurality.

Alec: But, of course, oppressive practices still hold sway, don't they?

Jaime: Yes. I chose to write a recent essay on challenging stigma within mental healthcare through my experiences in the LGBTu community. It wasn't until I created the photograph 'Bottled Up' (fig 1) that I realised I had not been able to express how societal heteronormativity impacted on me. Until that moment, the notion that my sexuality had been oppressed was an abstract concept that had no validity other than what was 'felt' by me. In producing the image it created a concrete embodied experience which I had not previously been able to articulate.

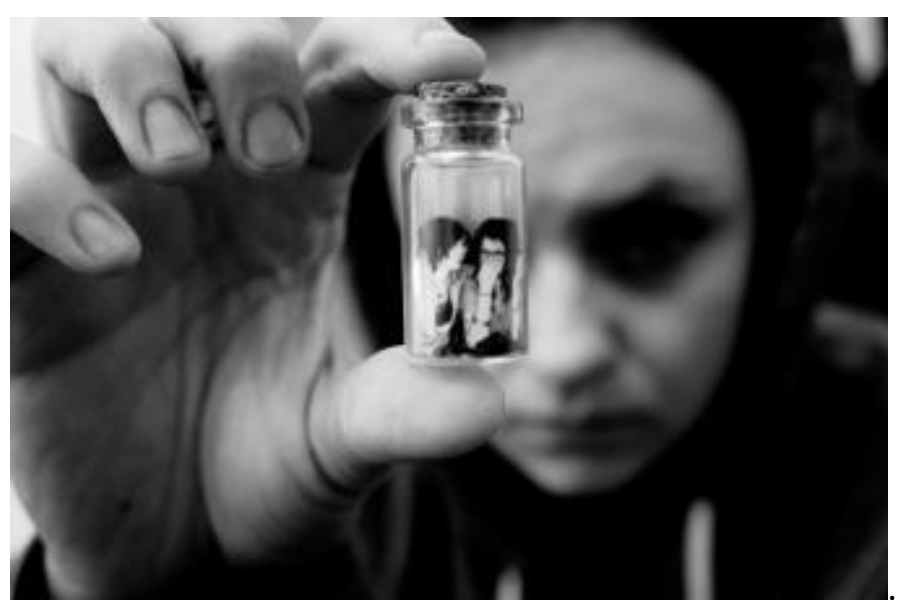


Fig 1 . y 'Bottled up' 2014

Alec: Although I'm a heterosexual man and don't claim to speak for the communities you both write from and about, what you say about the political history of the heteronormative psychiatrization of sexuality, Laetitia, and your related lived experiences of internalised stigma, Jaime, makes my blood boil. Your comments and experiences are testimony to the crucial role of narrative in causing, maintaining and becoming emancipated from human misery. Until 1974, The big $19^{\text {th }}$ century biomedicalized story of homosexuality as disease, in turn grounded in more enduring culturally normative stories, led both to the dreadful abuses you document Laetitia, later contesting and emancipatory narratives, and to the impact of heteronormativity on your embodied identities.

It seems to me that the narratives implicated in human distress are therefore very powerful. Little stories - how people make sense of their lives - can only be understood on the basis of the bigger stories, or discourses, that make those possible (Holstein and Gubrium 2000). So, on the basis of my area of scholarship, many mental health workers write about service users, drawing on a mixture of professional, diagnostic and lay narratives. These in turn, as you say Laetitia, are informed by broader cultural norms rooted in heteronormativity and other forms of cultural normativity. That's why people often get caught up in stories that misrepresent and do violence to their lived experience of themselves, in a kind of cruel narrative entrapment (Grant and Leigh-Phippard 2014, Grant et al in press). No wonder, then, that some people retreat, as you did Laetita in your South African past, in a state of personal, narrative invisibility. However, thankfully, as I described earlier, I believe it is possible to re-story one's life gradually, but in important ways, as you seem to have done through the use of photography, Jaime.

Jaime: I became aware that the impact of internalized homophobia has been identified as a contributing factor in the high levels of mental health difficulties within some LGBTU communities 
(Mayer et al 2014, Ross et al 2010). This perceived fear of homophobia can result in an individual suppressing or hiding their gendered and/or sexual identity from society in order to avoid negative consequences - what Goffman (1963) referred to as the management of a spoilt identity. In order to pass as 'normal', those stigmatized must conceal components of their identities with dreadful consequences (Orne 2013).

For example, in my youth work, Amy, a 19 year old a transgendered female, told me that she wished she could be 'non-recognisable'. When I asked her to expand on this, she said that she'd not disclosed her gender identity to anyone outside of the youth project. Although the project provided her with a safe space in which she could wear makeup, be known as 'Amy' and treated as a female, in the broader outside world she was known by her birth name and referred to as male.

We had a long discussion exploring what it meant for her to have such two conflicting gender identities. She told me that she had not had the opportunity to discuss this before, and that this and her involvement in the project gave her hope and a determination to pursue her identified gender as female into the future. This experience highlighted to me the importance of sharing stories and experiences in order to help LGBTU individuals consolidate and reconcile their identities in and with wider communities. From reading Butler (1999), I now believe that for as long as heteronormativity prevails within our society LGBTU people will have to continually live in the tension of either disclosing their gender and sexual identities or not.

The process of 'coming out' (Orne 2013) invites an LGBT person to engage with 'paradox of selfpreservation' (Healy 1993), in which they consider the consequences of stigma related to discrimination that follows on from their decision to come out. If someone thinks that the consequence of revealing their identity will result in significant personal loss or discomfort to them, then they are more likely to obscure their gendered or sexual identities, due to 'self surveillance' and 
'unspoken censorship' (Simon 2010). I was able to visualise this concept through the creation of the photograph, 'The paradox (fig. 2).

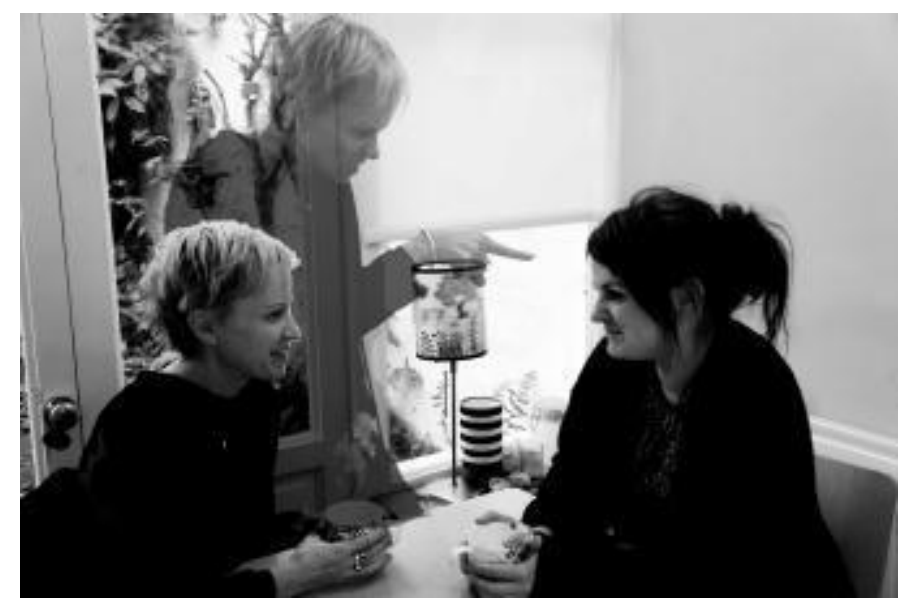

Fig 2 . y 'The Paradox' 2014

Such anticipated discrimination has detrimental effects on a person's wellbeing, in particular in relation to self-stigmatization (Thornicroft 2006). With reference to people with a psychiatric diagnosis, Thornicroft concludes that an individual's social identity is constructed on the basis of their individual perception of self and the perceived and actual reactions of others. Echoing Goffman, this often induces in them feelings of shame, hopelessness, depression, concern about the perceived behaviour of others, avoidance of social interactions with those considered 'normal', and inevitable detrimental effects on their self-esteem as a consequence. Thornicroft argues that the perception of probable discrimination may lead an individual to feel isolated, have low self-worth, and, ironically, increasingly withdraw from society in an attempt to avoid discrimination.

Alec: Yes, we need to be constantly mindful of the ways in which dominant forms of knowledge contribute to individual and community discriminating practices. We write about exclusionary tendencies in healthcare. In working to redress this state of affairs, queer and critical scholarship and research constantly aspires to the fulfilment of the social justice aim of widening the scope for social inclusion and citizenship. In this context, we argue that people achieve their experiences of 
themselves through forms of identity bestowed on them by society via a series of binaries (Zeeman et al 2014b).

Laetitia: In each binaried pair, for example health/illness, mentally ordered/disordered, straight/gay, male/female, the first term is always privileged and the second disparaged and frequently pathologized (Derrida 1978). The political aim of Queer scholarship is thus to disrupt such 'either or' thinking by invoking the relevance and significance of difference rather than pathology or deviance. This will hopefully pave the way for people from LGBTUI communities to increasingly create shared spaces separate from and free of the social power of normativity whereby they might otherwise be regarded as disordered.

Alec: It feels as if we've come full circle in our discussions at this point, so in drawing our paper to a close I wonder what each of you think are the implications for mental health practice emerging from our conversation? From my perspective, increased awareness of the relevance of Queer approaches for mental health practice, scholarship and research undoubtedly benefits LGBTUI communities in the context of the broader depathologizing agenda in mental health that I mentioned at the beginning of this paper. In line with Weeks (2000) and Plummer (1995), I believe that gendered and sexual identities can be supported, enhanced and made more generally socially understandable and acceptable through the use of narrative approaches. Stories of the lived experience of people who differ from the heterosexual norm are important in both challenging and pre-empting their marginalization.

Jaime: From my viewpoint it's important to constantly challenge the impact of heteronormative in our health care systems. The sharing of narrative experience increases the awareness of such impact, 
enabling mental health care practitioners and users to become what Gramsci (1971) describes as 'organic intellectuals' who work to produce change at public, grass roots levels. Health care education and research need to provide a platform in which future practitioners can consistently critique normative structures, in order to refute and disrupt the status quo.

Laetitia: From the onset of working on this paper, I did wonder how we as authors would overcome the heterosexual/homosexual binary reflected in our own gendered and sexual identities. I also wondered how, in a relational autoethnography, a heterosexual male could help LGBTUI people make a case for challenging the pathologizing of sexual and gender identities in mental health practice? I questioned whether such co-writing - where a heterosexual male lecturer speaks on behalf of a queer female lecturer and student - might in some ways re-inscribe the norm?

Thankfully, this could not have been further removed from my experience. On the contrary, the cowriting process was collaborative, challenging and enriching. It was made easier by us as authors cohering around a common goal of destabilising accepted norms in order to illuminate difference as a transformative device. In Queer scholarship, we unite around the political aim of disconnecting sexuality from pathologizing biomedical and broader cultural discourses. When we speak and write about gender and sexuality in non-normative ways, we create linguistic spaces and material practices where gender and sexual plurality becomes possible. In narrative visibility and re-storying, the lives of LGBTUI people become viable.

\section{References:}

Beasley C. (2005) Gender and sexuality: critical theories, critical thinkers. Sage Publications Ltd., London. 
Browne, K \& Lim, J. (2008) Count me in too. LGBT lives in Brighton and Hove. University of Brighton and Spectrum, Brighton,

Butler, J (1999) Gender trouble: Feminism and the subversion of identity. New York: Routledge.

Clarke V., Ellis S.J., Peel E. \& Riggs D.W. (2010) Lesbian, Gay, Bisexual, Trans \& Queer Psychology: An introduction. Cambridge University Press, Cambridge.

Cromby J., Harper D. \& Reavey P. (2013) Psychology, Mental Health and Distress. Palgrave Macmillan, Basingstoke.

Derrida J. 1978. Writing and difference. Chicago: University of Chicago Press.

Dickinson T. (2015) 'Curing queers': Mental nurses and their patients 1935 - 1974. Manchester University Press, Manchester.

Fernando S. (2011) Cultural Diversity and Racism: An Historical Perspective. In: De-Medicalizing Misery: Psychiatry, Psychology and the Human Condition. (ed Rapley, M., Moncrieff, J. \& Dillon, J.). Palgrave Macmillan, Basingstoke.

Foucault M. (1974) The archaeology of knowledge. Tavistock, London.

Foucault M. (1978) The history of sexuality. Penguin, London.

Giddens A. \& Sutton P.W. (2013) Sociology. Polity, Cambridge.

Goffman E. (1963) Stigma: Notes on the Management of Spoiled Identity. Penguin, London.

Gramsci A. $(1971,2005)$ Selections from the Prison Notebooks. Lawrence \& Wishart Limited, London. 
Grant 2013,

Grant and Leigh-Phippard 2014

Grant and Zeeman 2012

Grant et al 2013,

Grant et al in press

Halperin, D (1997) Sain Foucault: Towards a gay hagiography. Oxford: Oxford University Press.

Healy T. (1993) A Struggle for language: Patterns of self-disclosure in lesbian couples. Smith College Studies in Social Work. 63 (3), 247-264.

Holstein J.A. \& Gubrium J.F. (2000) The Self We Live By: Narrative identity in a postmodern world. Oxford University Press, New York.

Hunt, R \& Minsky, A (2007) Reducing health and inequalities for Lesbian, Gay and Bisexual people: Evidence of health care needs. Stonewall. London.

Johnstone L. (2014) A Straight Talking Introduction to Psychiatric Diagnosis. PCCS Books, Ross-onWye.

Mayberry M. (2013) Reducing Stigma of LGBT Youth Gay-Straight Alliances: Youth Empowerment and Working toward. [Online] Available from:

http://has.sagepub.com.ezproxy.brighton.ac.uk/content/37/1/35

[Accessed 20/01/14]

Mayer, K.H., Garofalo,R.,. Makadon, H,J. (2014). Promoting the successful development of sexual and gender minority youths. American Journal of Public Health 104, (6) (06): 976-81, http://search.proquest.com/docview/1538587454?accountid=9727 (Accessed 30/09/14, 2014). 
NHS choices. Mental health issues if you're gay [online] available from http://www.nhs.uk/Livewell/LGBhealth/Pages/Mentalhealth.aspx [accessed 01/06/14]

Orne, J. (2013) Queers in the Line of Fire: Goffman's Stigma Revisited. The Sociological Quarterly 54, 229-253.

Plummer K. (1995) Telling Sexual Stories: Power, Change and theSocial Worlds. Routledge, London.

Rapley M., Moncrieff J. \& Dillon J. (2011) De-Medicalizing Misery: Psychiatry, Psychology and the Human Condition. Palgrave Macmillan, Basingstoke.

Ross M. W., Smolenski D. J., Kajubi P., Mandel J. S., McFarland, W. \& Raymond, H. F. (2010).Measurement of internalized homo-negativity in gay and bisexual men in Uganda: Crosscultural properties of the Internalized Homonegativity Scale. Psychology, Health and Medicine. 15, $159-165$

Simon G. (2010) Self-supervision, surveillance and transgression. Journal of Family Therapy. 32(3), 308-325.

Thornicroft G. (2006) Shunned. Discrimination against people with mental illness. Oxford, Oxford University Press.

Timini S. (2011) Medicalising Masculinity. In: De-Medicalizing Misery: Psychiatry, Psychology and the Human Condition. (ed Rapley, M., Moncrieff, J. \& Dillon, J.). Palgrave Macmillan, Basingstoke.

Weeks J. (2000) Making Sexual History. Polity Press, Malden, MA. 
Zeeman et al 2014b 